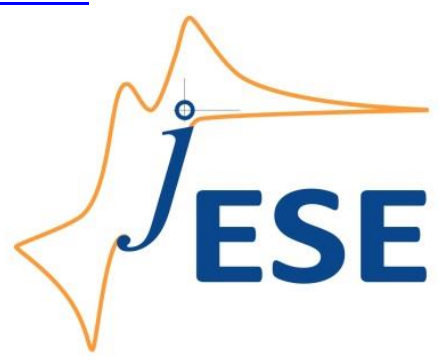

Open Access : : ISSN 1847-9286

www.jESE-online.org

Original scientific paper

\title{
Electrochemical behavior of tantalum in potassium hydroxide solutions
}

\section{Irena Mickova}

Faculty of Technology and Metallurgy, University "Ss. Cyril and Methodius" Rudjer Boskovic 16, 1000 Skopje, Republic of Macedonia

E-mail: mickova@tmf.ukim.edu.mk

Received: April 16, 2018; Revised: May 5, 2018; Accepted: May 10, 2018

\begin{abstract}
The electrochemical behavior of tantalum in various concentrations of $\mathrm{KOH}$ solutions $(0.1 \mathrm{M}-10 \mathrm{M})$, was investigated using the evolution of the open circuit potential in time, cyclic voltammetry and ellipsometric measurements. Depending on $\mathrm{KOH}$ concentrations, the open circuit potential measurements have shown three distinct behaviors concerning oxide film formation on the electrode surface and its dissolution. The cyclic voltammetry measurements were performed in various potential ranges, from -1.4 to $8 \mathrm{~V}$, different concentrations of $\mathrm{KOH}$ solutions $(0.1-10 \mathrm{M})$ and sweep rates ranging from $0.005 \mathrm{~V} / \mathrm{s}$ to $1 \mathrm{~V} / \mathrm{s}$. In the passive region, very stable passive films were formed, which reduction has not been possible during cathodic polarization even at highly concentrated $\mathrm{KOH}$ solutions. In the trans-passive region, the very strong peak at $1.65 \mathrm{~V}$ was monitored, which nature and chemical composition is still not well known.
\end{abstract}

\section{Keywords}

$\mathrm{Ta}$; $\mathrm{KOH}$; open circuit potentials; cyclic voltammetry; ellipsometry

\section{Introduction}

Tantalum is known as a refractory metal because its melting point of $2996{ }^{\circ} \mathrm{C}$ is greater than that of platinum $1750{ }^{\circ} \mathrm{C}$. In high temperature processes, tantalum is frequently used as a substitute of platinum and gold, which are more expensive. Tantalum also belongs to the group of valve metals because it develops a stable passivating layer spontaneously, when contacting air and/or water solutions. The resistance of valve metals against corrosion originates from the property of the passive film to regenerate sufficiently after an eventual breakdown [1-4]. Among the valve metals, $\mathrm{Ta}$ is known to be the most resistant metal, what is due to the quickly and cohesively formed passivating layer of the insulating amorphous $\mathrm{Ta}_{2} \mathrm{O}_{5}$. Also, $\mathrm{Ta}$ is the most corrosion resistant metal in common use today. 
In $21^{\text {st }}$ century, the primary use of $\mathrm{Ta}$ comes from its oxide $\mathrm{Ta}_{2} \mathrm{O}_{5}$ which has received a considerable attention as capacitors in the field of micro-electronics and integrated microtechnologies [5]. $\mathrm{Ta}_{2} \mathrm{O}_{5}$ thin films can be deposited by several methods, such as sputtering, anodic oxidation and chemical vapor deposition. In electrochemistry, the anodic oxidation of Ta and formation of $\mathrm{Ta}_{2} \mathrm{O}_{5}$ films was the subject of numerous investigations concerned with the growth of thin films in different acidic and neutral solutions [6-9]. So far, the passive and corrosion behavior of tantalum has been studied using several electrochemical techniques such as chronoamperometry [10], coulometry [11], linear polarization [12], cyclic voltammetry [13], galvanostatic polarization [14], electrochemical impedance spectroscopy (EIS), capacitance and photocurrent measurements [15-17]. Despite extensive literature data about the passive or corrosion behavior of Ta, studies concerned with the achievement of passivity in the presence of higher concentrations of alkaline media were scarcely carried out $[18,19]$ and thus, data on the behavior of Ta in strong alkaline media are very limited [20]. On the other hand, there still remain a number of questions concerning the influence of the forming electrolyte and its concentration on the stability of passive behavior of $\mathrm{Ta} / \mathrm{Ta}_{2} \mathrm{Ox}$-electrolyte systems which have not yet been addressed. The aim of this work is to present a more systematic study for enlarging the already existing domain of the influence of various parameters on the electrochemical behavior of $\mathrm{Ta}$ in $\mathrm{KOH}$ solutions. By investigating the evolution of open circuit potential (OCP) over time, in combination with in-situ ellipsometric measurements and cyclic voltammetry (CV) in larger concentration range of $\mathrm{KOH}$ solution and larger potential region in (CV) measurements, it is expected to obtain more information concerning formation and stability of passive films formed on Ta surfaces.

\section{Experimental}

\section{Electrodes}

Massive cylindrical Ta rods (Alfa Aesar, Johnson Matthey Company), with purity of $99.95 \%$ and diameter of $6.4 \mathrm{~mm}$, were cut in discs with thickness of $3 \mathrm{~mm}$ which served as the working electrodes. The discs were embedded into Teflon tubing holder of appropriate internal diameter, leaving the one basis with surface area of $0.32 \mathrm{~cm}^{2}$ to be exposed to electrolyte solution. Before each experiment, the electrode surfaces were mechanically polished using successively various grades metallographic emery papers (from 400 to 1200). After each experiment, the electrodes were mechanically re-polished and prepared for next measurements as described above. The counter electrode was a Pt spiral wire and the reference electrode was a saturated calomel electrode (SCE), having the contact provided through a bridge with a Luggin capillary filled with the test solution. All measured potentials are referred to the SCE.

\section{Electrolytic optical cell}

For simultaneous electrochemical and in-situ ellipsometric measurements, the special cell of the Pyrex glass vessel was used. It was equipped with three cylindrical compartments for the working, counter and reference electrode, as well as an inlet and an outlet for bubbling inert gas. Prior to each experiment, the electrolyte in the cell was de-aerated by flowing argon gas through a fritted bubbler for at least $30 \mathrm{~min}$ before the run.

\section{Solutions}

All experiments were carried out in $\mathrm{KOH}$ solutions with concentrations of $0.1,0.5,1.0,2,5$ and $10 \mathrm{M}$, prepared from $\mathrm{KOH}$ crystals p.a. Merck and triply distilled water. After each experiment, the electrolyte in the cell was exchanged in order to avoid any eventually formed soluble species. 


\section{Apparatus}

The electrochemical measurements were carried out using Autolab (model 128N) interfaced with PC. For ellipsometric measurements, the equipment was Thin Film Ellipsometer, Rudolph Research, type 43603-200 working at wavelength of $\lambda=546.1 \mathrm{~nm}$ and at ancidence angle of $\varphi=70^{\circ}$. More details on simultaneous electrochemical and in-situ ellipsometric measurements have already been described in our previous works on $\mathrm{Ti}$ and $\mathrm{Nb}$ [21].

\section{Results and discussion}

When Ta is handled in air, the electrode surface is always covered spontaneously by a natural oxide film. For a polished electrode, the film thickness tended to increase with increasing of exposure time and the film thickening was faster during initial 3 hours. It can be found in literature that the predominant constituent, about $88 \mathrm{~mol} \%$ of natural oxide film, is $\mathrm{Ta}_{2} \mathrm{O}_{5}$ formed as the outer layer. The remaining, a smaller fraction of about $12 \mathrm{~mol} \%$, is the inner sub-layer of the film that is primarily tantalum monoxide $\mathrm{TaO}$ [22].

\section{Evolution in time of the open circuit potential (OCP)}

For OCP measurements, after mechanical polishing, Ta electrodes were quickly transferred into electrolytic cell with desired concentration of $\mathrm{KOH}$, taking the immersion moment as zero time (Figure 1a). Simultaneously with OCP measurements, in-situ ellipsometric measurements were also performed (Figure 1b). The ellipsometric measurements showed that at time zero, the thickness of the oxide film spontaneously formed in atmospheric conditions is between 1 and $1.5 \mathrm{~nm}$.

Three distinct behaviors of Ta, depending on $\mathrm{KOH}$ concentration, can be noticed in Fig. 1: (i) thickening of natural oxide film with augmentation of electrode passivity, (ii) a continuation of film thickening followed by its dissolution and (iii) only dissolution of natural oxide film. In 0.1 and $0.5 \mathrm{M} \mathrm{KOH}$ solutions, the OCP shifted continuously to more positive values with time, illustrating the self-passivation processes on Ta electrode with thickening of the air-formed natural oxide film. The healing and further thickening of this film will occur until the steady-state conditions are achieved. The relative thickness $\Delta d$ of passive film on the primarily formed natural oxide film increases from about $1.2 \mathrm{~nm}$ in $0.1 \mathrm{M} \mathrm{KOH}$ and from about $0.8 \mathrm{~nm}$ in $0.5 \mathrm{M} \mathrm{KOH}$. The possible anodic reaction during the passivation and thickening of the natural oxide film is oxidation of the sub-layer of $\mathrm{TaO}$ into $\mathrm{Ta}_{2} \mathrm{O}_{5}$ :

$$
2 \mathrm{TaO}+6 \mathrm{OH}^{-} \rightarrow \mathrm{Ta}_{2} \mathrm{O}_{5}+3 \mathrm{H}_{2} \mathrm{O}+6 \mathrm{e}^{-}
$$

According to Figure $1 \mathrm{a}$, the OCP of Ta-solution system shows a parabolic variation with exposure time for $0.1 \mathrm{M}$ and $0.5 \mathrm{M} \mathrm{KOH}$ solutions, which may indicate the thickening of the oxide film. After $1500 \mathrm{~min}$ of exposure, the steady state conditions are attained. In $1.0 \mathrm{M} \mathrm{KOH}$ solution the OCP variation in time is also parabolic, but steady-state conditions are reached faster, approximately after $220 \mathrm{~min}$. In $2 \mathrm{M} \mathrm{KOH}$ solution, the process of passivation and thickening of oxide film begins first and the $O C P$ is shifted in positive direction forming a broad peak and then it slightly shifts in the reverse potential direction until the steady-state is reached. The broadening of the curve indicates that after longer exposure time, the dissolution of the film begins to be slightly predominant process in comparison with the thickening of oxide film. This is confirmed by ellipsometric measurements where $\Delta d$ firstly increases for about $0.4 \mathrm{~nm}$ and then decreases for about $0.2 \mathrm{~nm}$. In $5 \mathrm{M} \mathrm{KOH}$ solution, the OCP value shortly increases in a positive direction forming the maximum at $-910 \mathrm{mV}$. Formation of this maximum is associated with thickening of natural oxide film and its subsequent decrease for about $\Delta d=0.5 \mathrm{~nm}$, indicating a process of film dissolution where the natural oxide film is also partly dissolved. From the shapes of the OCP vs. time curves for $2 \mathrm{M}$ and $5 \mathrm{M} \mathrm{KOH}$, it is evident 
that the process of dissolution is faster in $5 \mathrm{M} \mathrm{KOH}$ than in $2 \mathrm{M} \mathrm{KOH}$. In $10 \mathrm{M} \mathrm{KOH}$ the $O C P$ is shifted only in a cathodic direction, indicating that the oxide film is subject of continuous dissolution. A. Robin [20] has already investigated evaluation of the OCP of Ta as a function of exposure time in $5-30 \% \mathrm{NaOH}$ solutions at room temperature and 50 and $75^{\circ} \mathrm{C}$. Here obtained OCP vs. time curves are similar to OCP curves presented by this author for lower and higher concentrations of alkali solutions and shorter exposure time.
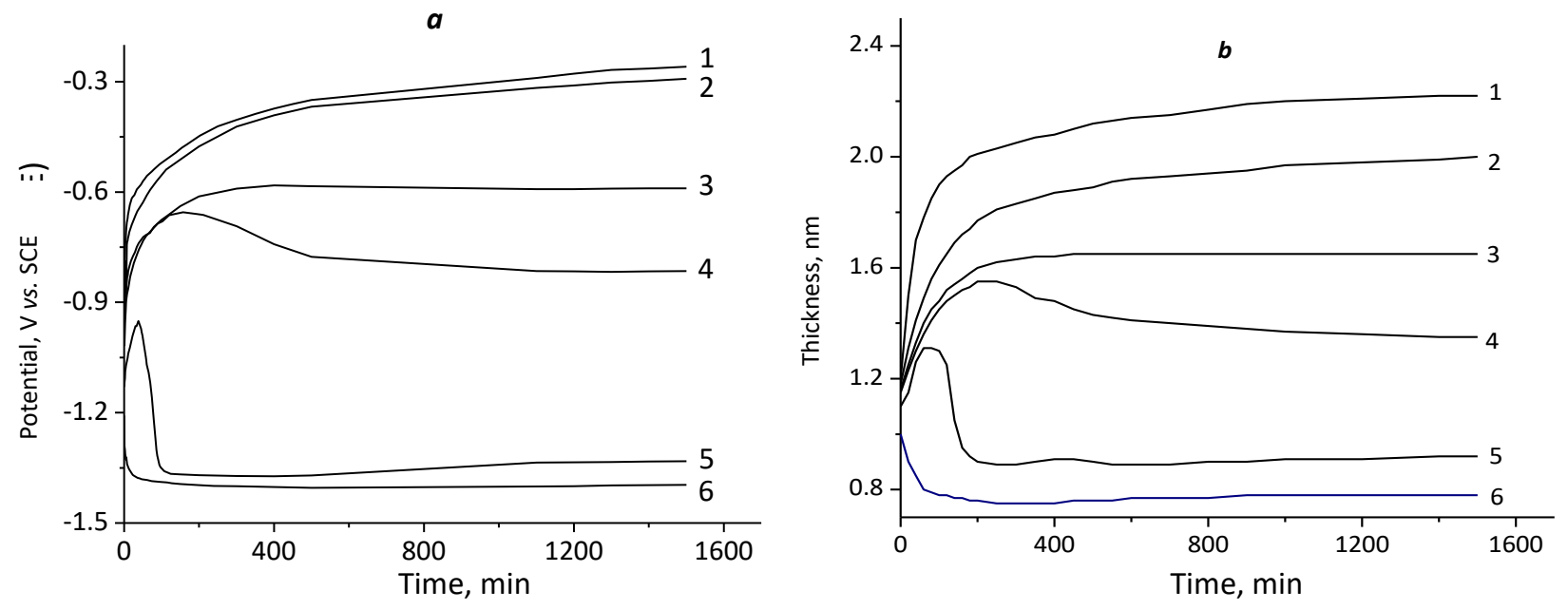

Fig. 1 Variation with exposure time of (a) OCP for Ta polished electrode in solution with different $\mathrm{KOH}$ concentrations, (b) film thickness determined by simultaneous ellipsometric in-situ measurements. $\mathrm{KOH}$ concentrations: $1-0.1 \mathrm{M}, 2-0.5 \mathrm{M}, 3-1 \mathrm{M}, 4-2 \mathrm{M}, 5-5 \mathrm{M}$ and $6-10 \mathrm{M} \mathrm{KOH}$

It can be noticed in Fig. 1 that for medium hydroxide concentrations, the OCP curves change their shapes for longer exposure time, indicating thus evolution of two distinct processes: thickening and dissolution of oxide film. The dissolution mechanism in higher concentrations of $\mathrm{NaOH}$ proposed in [20], should be also adequate for dissolution of the oxide film in higher concentrations of $\mathrm{KOH}$ :

$3 \mathrm{Ta}_{2} \mathrm{O}_{5}+8 \mathrm{KOH} \rightarrow \mathrm{K}_{8} \mathrm{Ta}_{6} \mathrm{O}_{19}+4 \mathrm{H}_{2} \mathrm{O}$

A subsequent anodic reaction may be the dissolution of Ta metallic substrate with precipitation of potassium isopolytantalate at steady-state conditions:

$6 \mathrm{Ta}+8 \mathrm{KOH}+30 \mathrm{OH}^{-} \rightarrow \mathrm{K}_{8} \mathrm{Ta}_{6} \mathrm{O}_{19}+19 \mathrm{H}_{2} \mathrm{O}+30 \mathrm{e}^{-}$

Cyclic voltammetry (CV)

Cyclic voltammetry (CV) studies on Ta were performed by potential scanning in various potential ranges (from -1.4 to $8 \mathrm{~V}$ ) in different concentrations of $\mathrm{KOH}$ solutions and scan rates ranging from 0.001 to $1 \mathrm{~V} / \mathrm{s}$. Typical cyclic voltammograms of $\mathrm{Ta}$ in $\mathrm{KOH}$ solution are shown in Figure 2.

The potential scan was initiated at $-0.85 \mathrm{~V}$, what is more negative potential than $O C P(-0.6 \mathrm{~V}$ in Fig. 1). In the first positive scan, a narrow active region followed by the passivation transition was observed in Figure 2. In the active region, where the anodic current peak at $-0.65 \mathrm{~V}$ is formed, the dissolution of metal substrate proceeding by an anodic process is described as:

$\mathrm{Ta} \rightarrow \mathrm{Ta}^{5+}+5 \mathrm{e}^{-}$

Dissolution rate of the process (4) is slower and the current of the active peak is quite smaller than were noticed for the anodic processes carried out under same conditions for the same sized electrodes of other valve metals $\mathrm{Ti}$ and $\mathrm{Nb}$ [23-25]. The electrode dissolution in the active region is followed by diffusion of $\mathrm{Ta}^{+5}$ ions, undergoing through the pores of oxide film from the metal substrate to the electrolyte. 


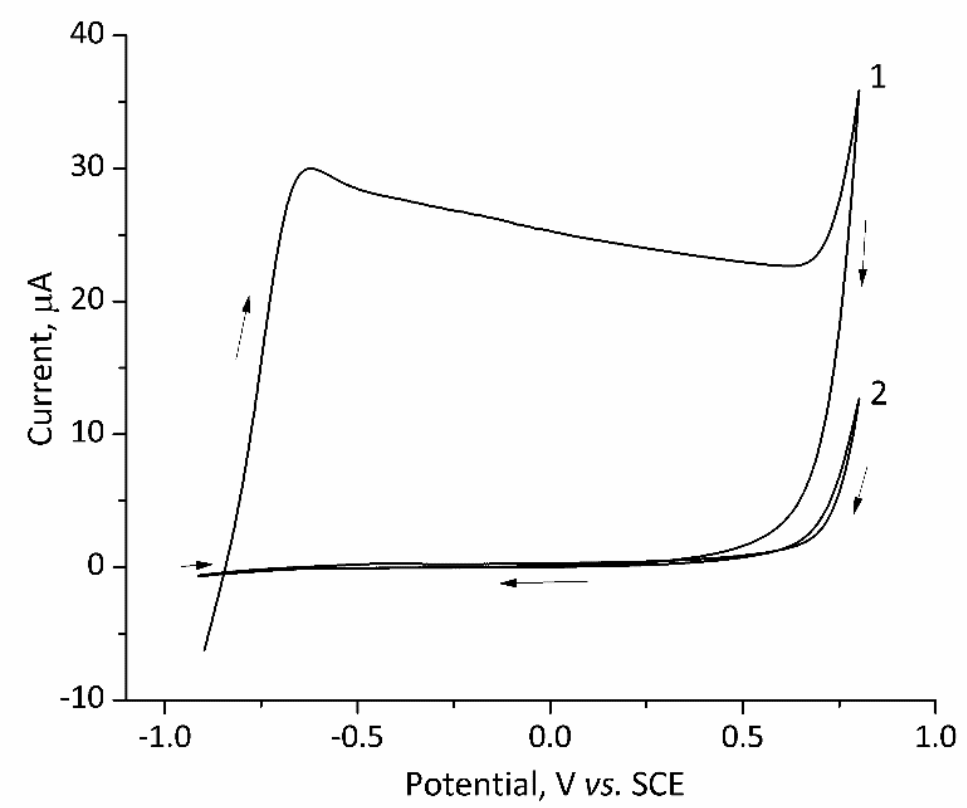

Fig. 2. Typical cyclic voltammograms of Ta electrode recorded in $1.0 \mathrm{M} \mathrm{KOH}$ solution at $10 \mathrm{mV} / \mathrm{s}: 1$ - first cycle, 2 - second cycle

For more positive potentials than $-0.65 \mathrm{~V}$, the anodic current begins to decrease forming a passive region. In the passive region, the metal dissolution by reaction (4) is hindered and the thickness of anodic oxide film on Ta grows according to the following reaction:

$2 \mathrm{Ta}+10 \mathrm{OH}^{-} \rightarrow \mathrm{Ta}_{2} \mathrm{O}_{5}+5 \mathrm{H}_{2} \mathrm{O}+10 \mathrm{e}^{-}$

Reaction (5) preferentially takes place when anodic current appears in the first positive CV scan [12]. The passive region extends over a potential range from approximately $-0.55 \mathrm{~V}$ to $0.65 \mathrm{~V}$ and then the current begins to increase quickly, leading to a trans-passive region. In the first reverse potential scan, the current decays gradually without any peak observed in the CV curve, indicating that the anodic oxide film formed in the first positive scan remained stable. In the second and next subsequent potential scans, large current plateaus with values of current close to zero for both forward and reverse scans were recorded. It is evident that after the first positive scan, the Ta electrode remained passive in the whole investigated potential region. The passive film formed in the first positive potential scan blocked all possible redox reactions and further dissolution of Ta, minimizing thus transfer of $\mathrm{Za}{ }^{5+}$ ions into the electrolyte.

\section{Effect of potential scanning range}

In order to get more valuable information about possible redox reactions on the Ta electrode in various concentrations of $\mathrm{KOH}$ solution, the potential scanning range was enlarged from $-1.4 \mathrm{~V}$ to 8 $\mathrm{V}$. At the initial cathodic potential of $-1.4 \mathrm{~V}$, a considerable cathodic current was observed due to the evolution of hydrogen on the electrode surface. A part of hydrogen which is generated on the Ta electrode is adsorbed on the electrode surface as $\mathrm{H}$ atoms. When their amount becomes larger, the hydrogen will be liberated by electrochemical desorption forming $\mathrm{H}_{2}$ gas (Heyrovski step) [23]:

$$
\mathrm{H}_{2} \mathrm{O}+\mathrm{H}_{\mathrm{ads}}+\mathrm{e}^{-} \rightarrow \mathrm{H}_{2}+\mathrm{OH}^{-}
$$

The total hydrogen evolution reaction can be described as:

$$
2 \mathrm{H}_{2} \mathrm{O}+2 \mathrm{e}^{-} \rightarrow \mathrm{H}_{2}+\mathrm{OH}^{-}
$$

Figure 3 presents CVs recorded at shorter potential range up to $-0.5 \mathrm{~V}$, just after apparition of anodic peak in the passive region where smaller thickness of the passive film is formed. 


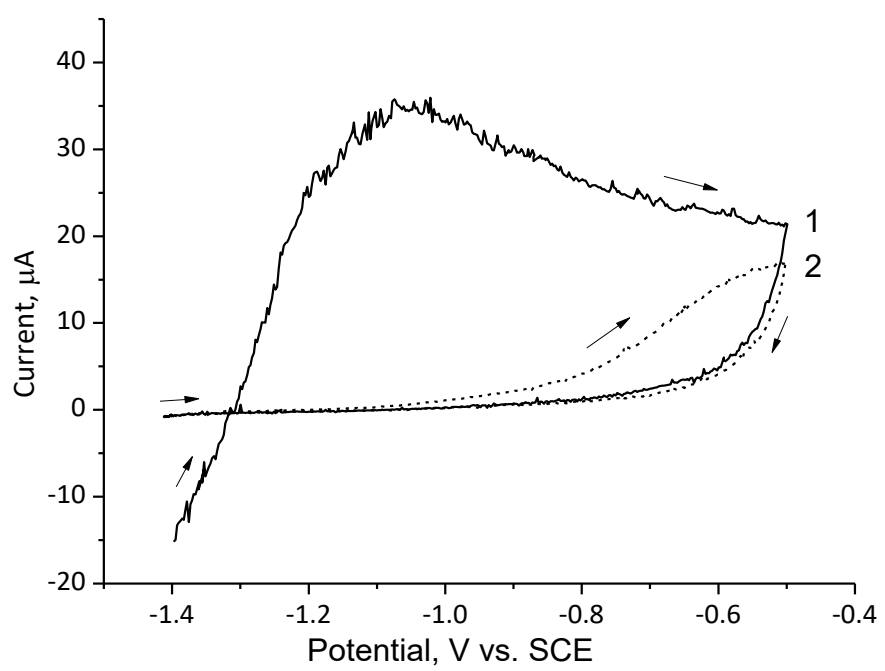

Fig. 3. Two cycles of cyclic voltammograms of Ta electrode recorded in $10 \mathrm{M} \mathrm{KOH}$ at $2 \mathrm{mV} / \mathrm{s}$ : 1 - first cycle, 2 - second cycle

At slow scan rates as $2 \mathrm{mV} / \mathrm{s}, \mathrm{CV}$ in Figure 3 showed an active region with relatively big current oscillations observed as a result of high ohmic resistance of the Ta surface. The slow scan rate was applied specially for the reason that after finishing of the activation process, the electrode surface would have, in the reverse of cycle 1, enough long time for electrochemical dissolution of very thin passive layer formed. Since in the anodic scan of cycle 2, the apparition of reactivation peak is missing, it can be concluded that even in the very high concentration of $\mathrm{KOH}$, there is no appearance of dissolution of passive films. The same has already been observed for $\mathrm{Nb}$ and $\mathrm{Ti}[25,26]$. After the first cycle, the electrode was kept at $-1.4 \mathrm{~V}$ for $30 \mathrm{~min}$ and the second cycle was recorded to verify if the passive film formed in the first cycle could be reduced at $-1.4 \mathrm{~V}$. However, in the forward scan of the second cycle, only a current plateau with a small increase of the current at the end of the anodic potential is observed, indicating that the activation process has not been fully finished in the first cycle. From these results, it can be concluded that Ta is more resistant in strong alkaline solution than $\mathrm{Ti}$ and $\mathrm{Nb}$ [27-29]. Using a number of CV experiments it was approved that at the beginning of CV measurements, various cathodic currents generated by the initially applied cathodic potential, influenced negligibly to the shape of CV curves. Therefore, our further measurements started at the cathodic potentials where small currents were recorded at the beginning of measurements, avoiding thus hydrogen evolution and bubbles rolls across electrode surface.

Figure 4 presents CV curves recorded for a larger range of anodic potentials up to $8 \mathrm{~V}$. Figure $4 \mathrm{a}$ shows that in the trans-passive region of potentials, the strong peak appears at $1.65 \mathrm{~V}$ for which a nature and chemical composition are still unknown, in spite of some theoretical explications that have already been given [30,31]. It is known that abnormal increase of current density in the transpassive region under some specific conditions such as applied potential, $\mathrm{pH}$ of the electrolyte, presence of active anions etc., is often associated with the local breakdown of the passive film. The process of the local breakdown represents the metal dissolution with the rate depending on the chemical energy stored in the system. There are spontaneous local increases of the film conductivity, which is sometimes higher by many orders of magnitude. In that a case, the passive film can be simulated as dielectric medium of a capacitor which is short circuited by the local breakdown. One of the explication of the current peak located at $1.65 \mathrm{~V}$ could be a localized dissolution of Ta associated with the local breakdown process in the passive film which provokes an increase of the anodic current. If the film breakdown is associated with the film repair and its repassivation, the current begins to decrease forming a current peak. 
Figure $4 \mathrm{~b}$ shows sequences of $\mathrm{CV}$ measurements where the final anodic potential on $\mathrm{Ta}$ in $0.5 \mathrm{M} \mathrm{KOH}$ was gradually increased in each next cycle. All subsequent CVs started from and returned to the same cathodic potential of $-1.4 \mathrm{~V}$. Single difference in these measurements is only the limit of anodic potential. The progress of the film thickness growth with anodic potential may take place only if the actual applied potential exceeds the maximum of potential value attained in the previous cycle. For each sequence, the film thickness grows in the first forward scan and has constant value in the reverse scan. For each next sequence, in the first forward scan the film thickness has constant value up to the end of previous cycle and then continues to grow up to the final anodic potential. It is evident that by gradually increasing final anodic potential value, the passive film grows again.
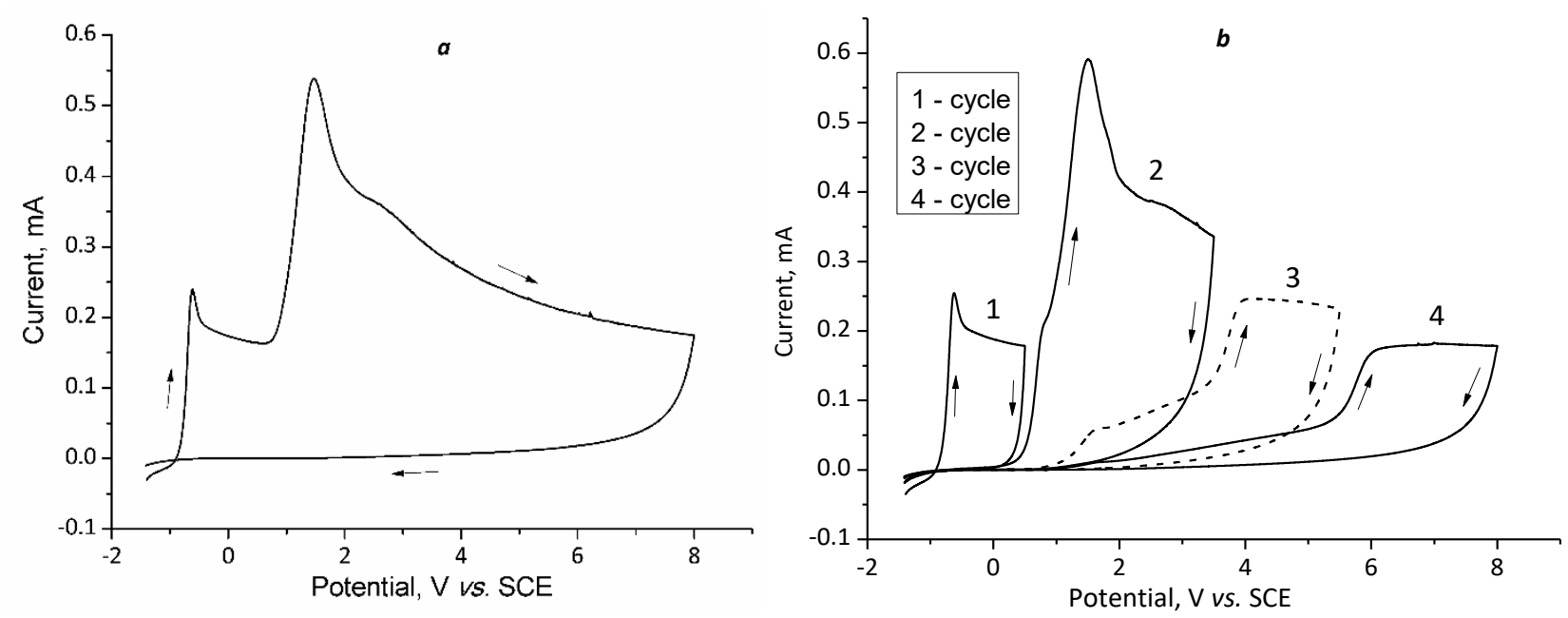

Fig. 4 Cyclic voltammograms of Ta electrode recorded in $0.5 \mathrm{M} \mathrm{KOH}$ at $50 \mathrm{mV} / \mathrm{s}$ : (a) first cycle,

(b) multiple cycles at gradual increasing of final anodic potential

The shapes of the sequences recorded in Figure $4 \mathrm{~b}$ represent just copy segments of the corresponding voltammogram recorded from the starting potential at $-1.4 \mathrm{~V}$ to the final potential at $8 \mathrm{~V}$ at once (Fig. 4a). The experiments shown in Figure $4 \mathrm{~b}$ confirm the barrier properties of anodic oxide film built on the Ta surface. They also confirm that the localized dissolution of Ta by local breakdown process which is associated with repair of the film and its re-passivation is only possible for the film thickness built at the anodic potential higher than $1.65 \mathrm{~V}$. This can be concluded because in reverse scans, the reactivation peak at $1.65 \mathrm{~V}$ does not exist, as in the forward scan. Using photoelectrochemical measurements, it has already been shown that the current peak around $1.65 \mathrm{~V}$ of abnormal intensity appears under the influence of an applied voltage, corresponds to the energy of the band-gap and can be related to the transition from semi-conducting to dielectric behavior of the film [32]. This current peak with abnormal intensity was also investigated by Silva et al. [33]. Using polarization curves and capacity measurements, as well as atomic force imaging microscopy (AFM), these authors concluded that appearance of the peak at $1.65 \mathrm{~V}$ is generated only from the relationship between surface state and film growth. Cavigliasso et al., have investigated electrochemical passivation of Ta electrode in various electrolytes by CV measurements in the potential range from 0 to $8 \mathrm{~V}$ [15]. For $\mathrm{NaOH}$ and also for some acid solutions, the peak at $1.65 \mathrm{~V}$ was missing. Ta electrodes used by these authors, however, were firstly mechanically and then chemically polished in the mixture containing $\mathrm{HF}, \mathrm{HNO}_{3}$ and $\mathrm{H}_{2} \mathrm{SO}_{4}$, which is different from the way of preparation applied in this work. One can therefore conclude that surface preparation of Ta plays an important role on the profile of the recorded CV curves. 


\section{Effect of $\mathrm{KOH}$ concentration}

The effect of $\mathrm{KOH}$ concentration $(C)$ on the peak potential $(E p)$ and peak current $(I p)$ of anodic peak was investigated for scan rates from $5 \mathrm{mV} / \mathrm{s}$ to $1 \mathrm{~V} / \mathrm{s}$. The potential sweep was initiated at $-1.4 \mathrm{~V}$, where at the beginning small cathodic currents for all investigated concentrations of $\mathrm{KOH}$ were observed (Figure 5).

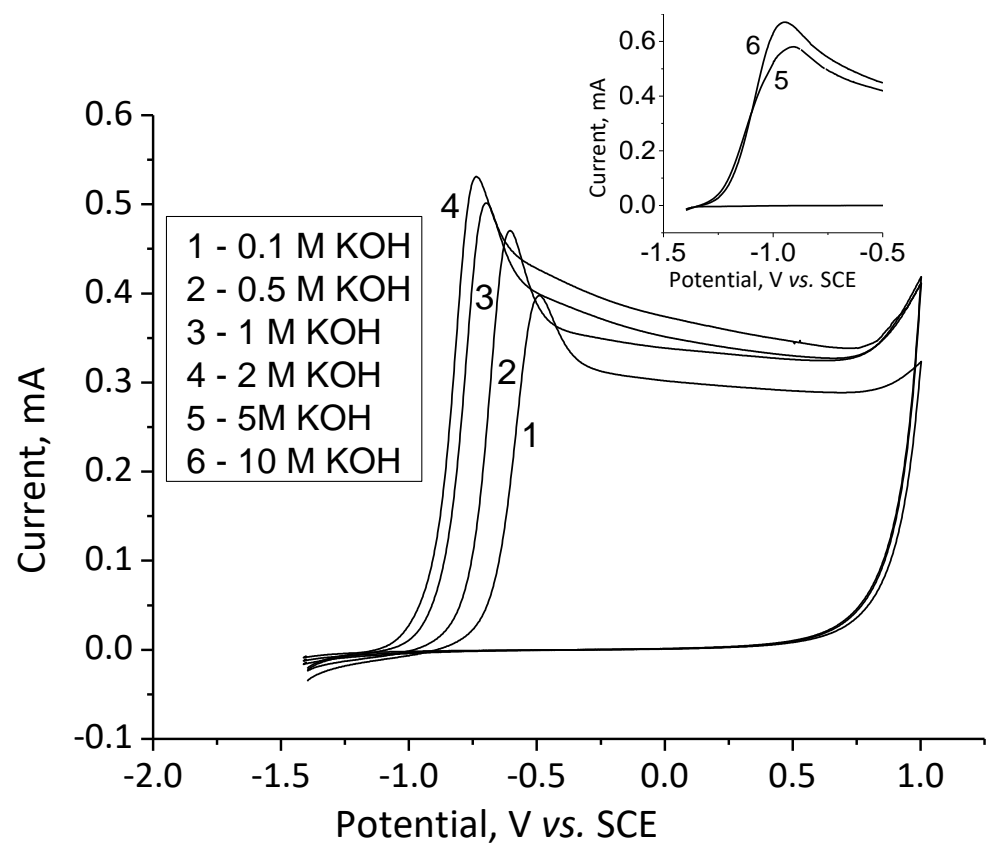

Fig. 5. Cyclic voltammograms of Ta electrode recorded in various concentrations of $\mathrm{KOH}$ solutions at $0.1 \mathrm{~V} / \mathrm{s}$

Figure 5 shows that for increased $\mathrm{KOH}$ concentration, the height of the maximum anodic current $\left(I_{\mathrm{p}}\right)$ is noticeable increased, while its corresponding primary passivation potential $\left(E_{\mathrm{p}}\right)$ is shifted towards more negative potential values, indicating enhancing of the rate of Ta dissolution.

From Figure 5, Figures 6 and 7 were constructed presenting plots of $E_{\mathrm{p}}$ and $I_{\mathrm{p}}$ on logarithm of $\mathrm{KOH}$ concentration.

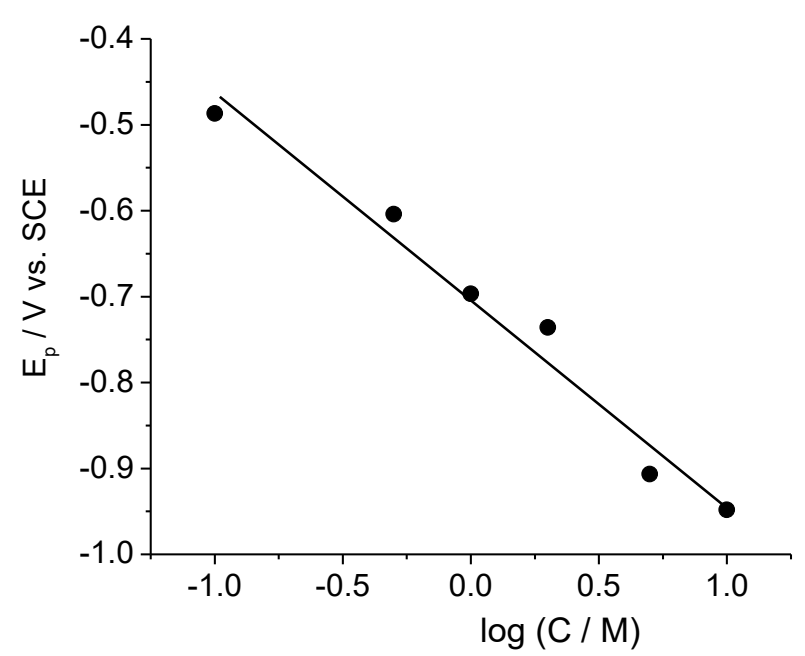

Fig. 6. Dependence of primary passivation potential Ep on the logarithm of $\mathrm{KOH}$ concentration at $0.1 \mathrm{~V} / \mathrm{s}$

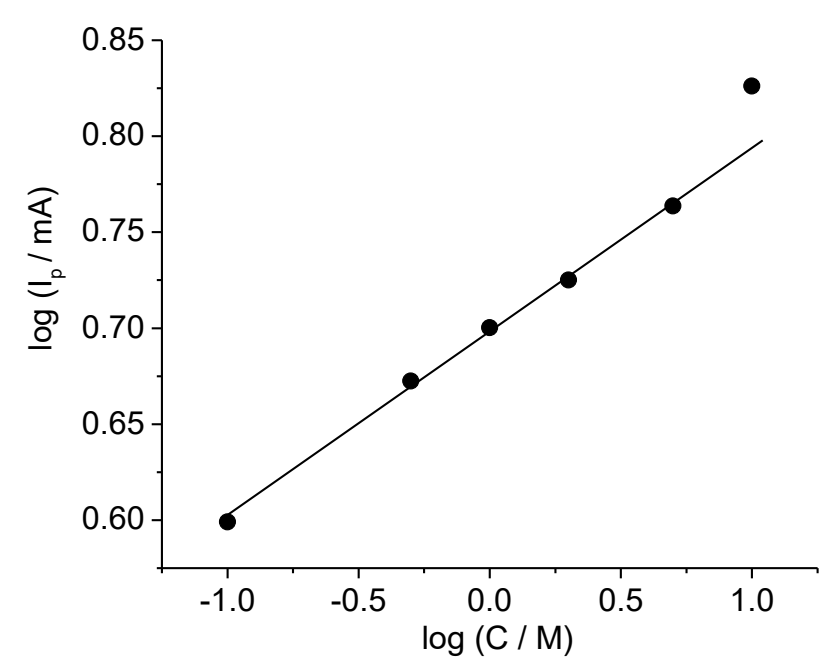

Fig. 7. Dependence of primary anodic current Ip on the logarithm of $\mathrm{KOH}$ concentration at $0.1 \mathrm{~V} / \mathrm{s}$

Figure 6 shows linear dependence with the slope of $\mathrm{d} E_{\mathrm{p}} / \mathrm{dlog} C=-0.244 \mathrm{~V} / \mathrm{dec}$. An obvious negative shift of $E_{\mathrm{p}}$ is observed at increasing $\mathrm{KOH}$ concentration. According to Figure 7, the 
dependence of primary anodic current $I p$ on the concentration of $\mathrm{KOH}$ is linear up to $5 \mathrm{M} \mathrm{KOH}$ and then shifts to higher value of $l_{p}$, indicating that for $10 \mathrm{M} \mathrm{KOH}$ dissolution of Ta rapidly increases.

\section{Effect of potential sweep rate}

The effect of the potential sweep rate $(v)$ on potentiodynamic polarization responses for Ta electrode in $1 \mathrm{M} \mathrm{KOH}$ is shown in Figure 8. The recorded voltammograms confirm the strong influence of sweep rate to the dissolution of Ta and the growth rate of the oxide film formed on Ta. The maximal anodic currents at the primary passivation potential are noticeable increased with increasing the sweep rate.
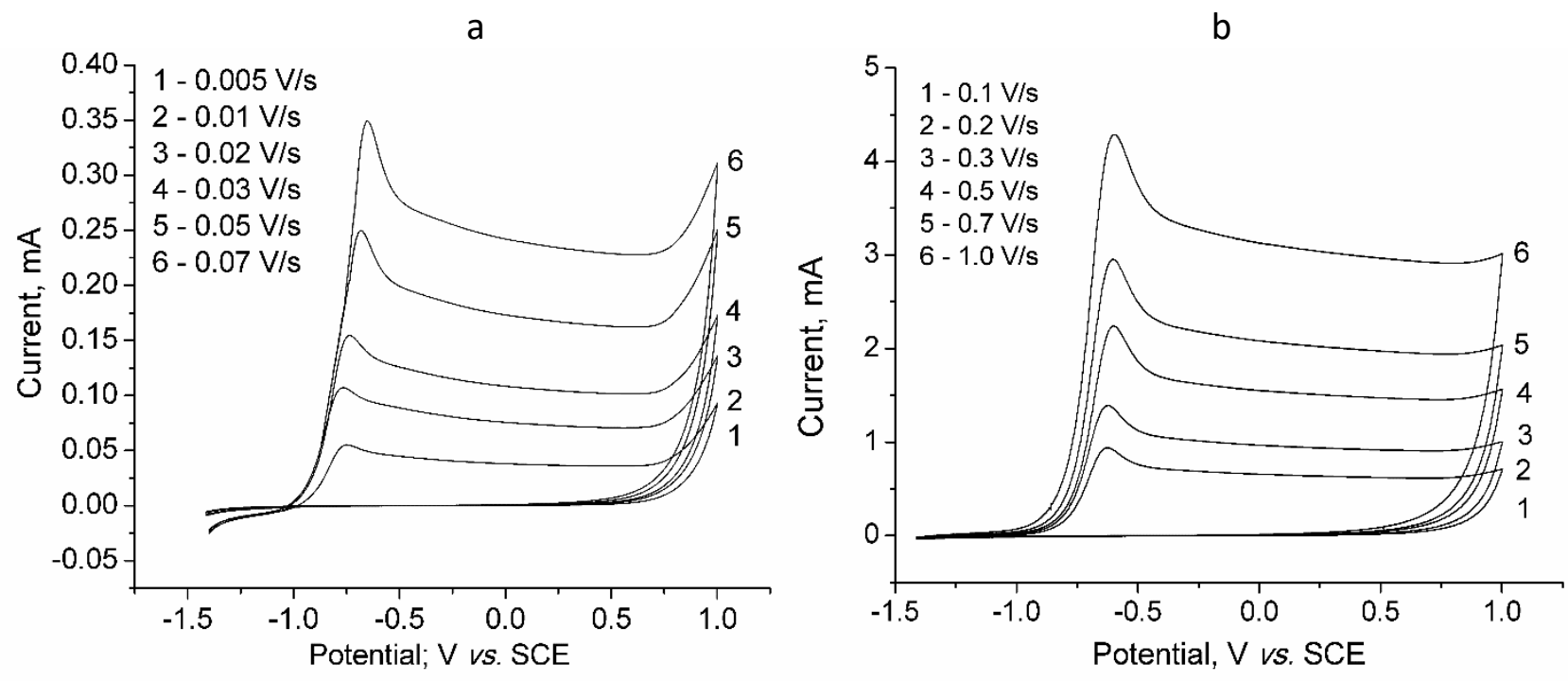

Fig. 8. Cyclic voltammograms of Ta recorded in $1 \mathrm{M} \mathrm{KOH;} \mathrm{(a)} \mathrm{for} \mathrm{sweep} \mathrm{rate} \mathrm{from} 0.005$ to $0.07 \mathrm{~V} / \mathrm{s}$,

(b) for sweep rate from 0.1 to $1 \mathrm{~V} / \mathrm{s}$

On the other hand, the primary passivation potential $E p$ is slightly shifted to more positive potentials as suggested in Figure 9 by the linear fit of $E p$ versus $\log (v)$ with a slope of $0.093 \mathrm{~V} / \mathrm{dec}$. Relatively low value of the slope in comparison with other valve metals indicates very low dissolution rate of Ta. The plots of primary anodic currents Ip against the square root of sweep rate are shown in Figure 10.

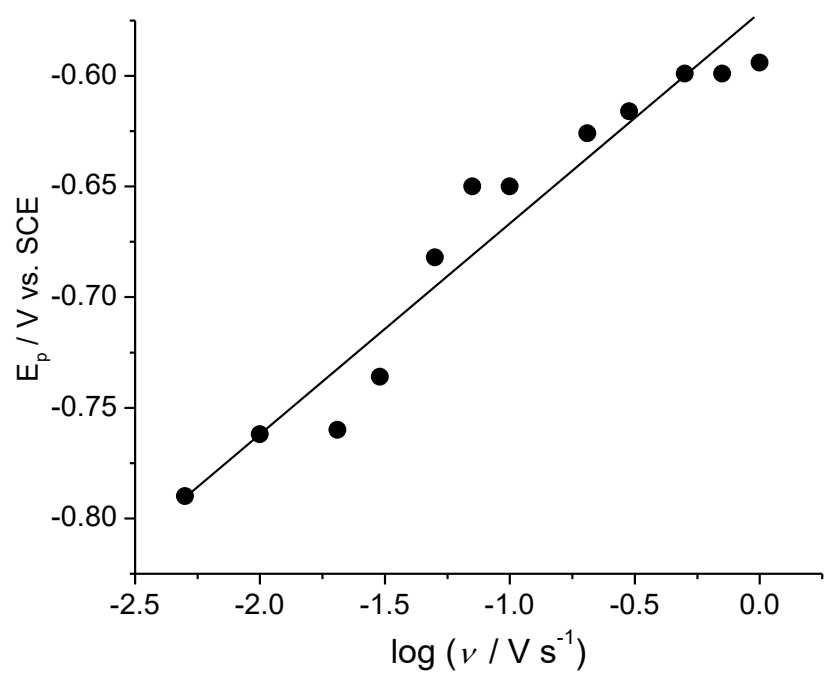

Fig. 9. Dependence of primary passivation potential of Ta electrode in $1 \mathrm{M} \mathrm{KOH}$ on logarithm of the sweep rate

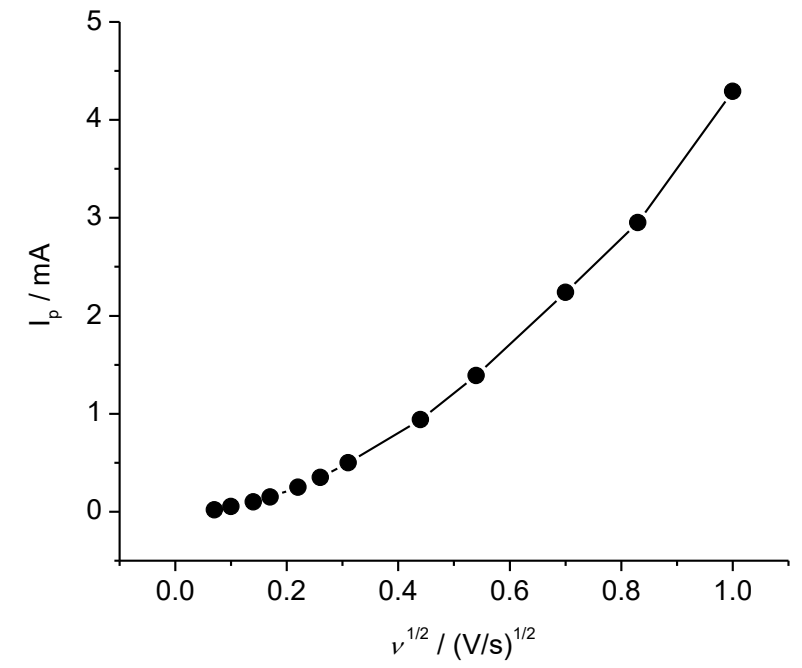

Fig. 10. Dependence of primary current of $T a$ electrode in $1 \mathrm{M} \mathrm{KOH}$ on on logarithm of the sweep rate the square root of the sweep rate 
For $1 \mathrm{M} \mathrm{KOH}$, the plot is not a straight line passing through origin. Similar shapes of $I p v s . v^{1 / 2}$ plots to this presented in Figure 10, were also obtained for Ta in 0.1 - $10 \mathrm{M} \mathrm{KOH}$ solutions, suggesting that formation/dissolution of passive films on Ta electrode is not a purely diffusion-controlled process.

\section{Conclusions}

- The OCP potential-time profiles revealed three distinct behaviors of Ta depending on $\mathrm{KOH}$ solution concentrations: (i) thickening of oxide film with enhancement of electrode passivity for $0.1,0.5$ and $1.0 \mathrm{M} \mathrm{KOH}$ solutions, (ii) thickening of the oxide film followed by its dissolution in 2 and $5 \mathrm{M} \mathrm{KOH}$ solutions and (iii) only dissolution of oxide film in $10 \mathrm{M} \mathrm{KOH}$.

- The cyclic voltammetry profiles in all investigated concentration of $\mathrm{KOH}$ solutions revealed the active/passive transition; the formed passive films are stable and do not undergo any reduction processes in the reverse scan.

- For larger anodic potential up to $8 \mathrm{~V}$, the anodic peak was recorded at $1.65 \mathrm{~V}$ which is located in trans-passive region. The origin of this peak was explained by local breakdown of passive film and dissolution of metal support. The film breakdown was associated with re-passivation and reparation of the film, so the current has begun to decrease forming the current peak.

- The effect of $\mathrm{KOH}$ concentration on the cyclic voltammetry profiles has shown that with the increase of $\mathrm{KOH}$ concentration the value of peak current Ip was increased, indicating an increasing rate of Ta dissolution. At the same time, the corresponding $E p$ values were shifted towards more negative potentials.

- The effect of potential sweep rate confirms a strong influence of the sweep rate on dissolution of Ta support. The formation/dissolution of passive films on Ta electrode is not purely diffusion controlled process.

\section{References}

[1] T. P. Hoar, Corrosion Science 7(6) (1967) 341-335

[2] H. S. Isaacs, Corrosion Science 29(2-3) (1989) 313-323

[3] J. Albella, I. Montero, J. Martinez-Duart, Thin Solid Films 125(1-2) (1985) 57-62

[4] B. MacDougall, M.J. Graham, Growth and Stability of Passive Films, in Corrosion Mechanisms in Theory and Practice, Second Edition, P. Marcus (Ed.), Marcel Dekker, New York (2002) 189-216

[5] C. Chaneliere, J. L. Autran, R. A. B. Devine, B. Balland, Materials Science and Engineering 22(6) (1998) 269-322

[6] V. Macagno, J.W. Schultze, Journal of Electroanalytical Chemistry and Interfacial Electrochemistry 180(1-2) (1984) 157-170

[7] R. Dreiner, K. Ehovec, J. Schimmet, Journal of the Electrochemical Society 112(4) (1965) 395-401

[8] S. Hornkjol, Electrochimica Acta 36(9) (1991) 1443-1446

[9] Q. Lu, S. Mato, P. Skeldon, G. E. Thompson, D. Masheder, H. Habazaki, K. Shimizu, Electrochimica Acta 47(17) (2002) 2761-2767

[10] J. Trompette, L. Massot, Corrosion Science 57(1) (2011) 174-181

[11] W. Wilthelmsen, Electrochimica Acta 33(1) (1988) 63-67

[12] J. P. Zheng, B. K. Klug, D. Roy, Journal of the Electrochemical Society 155(5) (2008) H341-H350

[13] H.P. Yang, S. H. Yang, Y. N. Cai, G. F. Hou, J. Y. Xia, M. T. Tang, Transactions of Nonferrous Metals Society of China 21(1) (2011) 179-184

[14] L. Young, Journal of The Electrochemical Society 124(4) (1977) 528-529

[15] G. Cavigliasso, M. Esplandiu, V. Macagno, Journal of Applied Electrochemistry 28(11) (1988) 12131219

[16] A. C. Manea, M. Buda, T. Visan, U. P. B. Scientific Bulletin Series B 72(4) (2010) 65-78 
[17] A. D. Modestov, A. D. Davydov, Journal of Electroanalytical Chemistry and Interfacial Electrochemistry 460(1-2) (1999) 214-225

[18] A. Gad Allah, W. Badawy, H. Rehan, Journal of Applied Electrochemistry 19(5) (1989) 768-776

[19] A. Fattah-Alhoseini, F. R. Attarzadeh, S. Vafeian, M. Hagshenas, M. K. Keshavarz, Int. Journal of Refractory Metals and Hard Metals 64 (2017) 168-175

[20] A. Robin, Journal of Applied Electrochemistry 33(1) (2003) 37-42

[21] Lj. Arsov, I. Mickova, Journal of Electrochemical Science and Engineering 5(4) (2015) 221-230

[22] O. Kerrec, D. Devilliers, H. Groult, M. Chemla, Electrochimica Acta 40(6) (1995) 719-724

[23] I. Mickova, A. Prusi, T. Grchev, Lj. Arsov, Croatica Chemica Acta 79(4) (2006) 527-532

[24] Lj. Arsov, Electrochimica Acta 27(6) (1982) 663-672

[25] A. Prusi, Lj. Arsov, Corrosion Science 33(1) (1992) 153-164

[26] I. Mickova, International Review of Chemical Engineering 3(5) (2011) 550-562

[27] A. Prusi, Lj. Arsov, B. Haran, B. Popov, Journal of the Electrochemical Society 149(11) (2002) B491B498

[28] I. Arsova, Lj. Arsov, N. Hebestreit, A. Anders, W. Plieth, Journal of Solid State Electrochemistry 11(2) (2007) 209-214

[29] M. A. Ibrahim, D. Pongkao, M. Yoshimura, Journal of Solid State Electrochemistry 6(5) (2002) 341-350

[30] I. Montero, M. Fernandez, J.M. Allbela, Electrochim. Acta 32(1) (1987) 171-174

[31] M. M. Lohrengel, Electrochim. Acta 39(8-9) (1994) 1265-1271

[32] R. A. Silva, M. Walls, B. Rondot, M. Da Cuhna Bello, R. Guidoin, Journal of Material Science; Materials in Medicine 13(5) (2002) 495-50

[33] R. A. Silva, I. P. Silva, B. Rondot, Journal of Biomaterials Applications 21(1) (2006) 93-103

(C)2018 by the authors; licensee IAPC, Zagreb, Croatia. This article is an open-access article distributed under the terms and conditions of the Creative Commons Attribution license (http://creativecommons.org/licenses/by/4.0/) 